\title{
SAFETY AND TOLERABILITY OF LOW DOSE NALTREXONE THERAPY IN CHILDREN WITH MODERATE TO SEVERE CROHN'S DISEASE: A PILOT STUDY
}

\author{
Jill P. Smith, M.D.., Douglas Field, M.D. ${ }^{\star}$, Sandra Bingaman, R.N. ${ }^{*}$ Robert Evans, M.D. , and \\ David Mauger, Ph.D. ${ }^{\prime}$ \\ *Department of Medicine, Pennsylvania State University, College of Medicine, Hershey PA \\ †Department of Pediatrics, Pennsylvania State University, College of Medicine, Hershey PA \\ ‡Department of Public Health Sciences. Pennsylvania State University, College of Medicine, \\ Hershey PA
}

\section{Abstract}

Background-There is an unmet need for safe and effective medicines to treat children with Crohn's disease. Recently, investigations have shown an association between endogenous opioid peptides and inflammatory cells.

\begin{abstract}
Aims-The aims of this study were to evaluate the safety and tolerability of an opioid antagonist, naltrexone, in children with moderate to severe Crohn's disease.

Methods-A pilot clinical trial was conducted in children with moderate to severe Crohn's disease. Fourteen subjects with a mean age of 12.3 years $(8-17$, range) were enrolled. Children were randomized to placebo or naltrexone $0.1 \mathrm{mg} / \mathrm{kg}$ orally for 8 weeks followed by open-labeled treatment with 8 additional weeks of naltrexone. Safety and toxicity were monitored by physical examinations and blood chemistries. Clinical activity was assessed by the PCDAI (Pediatric Crohn's Disease Activity Index) and Quality of life was monitored by the Impact III survey.
\end{abstract}

Results-Oral naltrexone was well tolerated without any serious adverse events in children with moderate to severe Crohn's disease. PCDAI scores significantly decreased from pretreatment values (34.2 \pm 3.3$)$ with an eight-week course of naltrexone therapy $(21.7 \pm 3.9)(\mathrm{p}=0.005)$. Twentyfive percent of those treated with naltrexone were considered in remission (score $<10$ ) and 67\% had improved with mild disease activity (decrease PCDAI score by at least 10 points) at the end of the study. Systemic and social quality of life improved with naltrexone treatment $(\mathrm{p}=0.035)$.

Conclusions-Naltrexone therapy appears safe with limited toxicity when given to children with Crohn's disease and may reduce disease activity.

Corresponding Author: Jill P. Smith, MD, Professor of Medicine, Department of GI Medicine, H-045, 500 University Drive, Pennsylvania State University, College of Medicine, Hershey, PA 17033, PH: 717-531-3694, FAX: 717-531-6770, jsmith2@ psu.edu. Publisher's Disclaimer: This is a PDF file of an unedited manuscript that has been accepted for publication. As a service to our customers we are providing this early version of the manuscript. The manuscript will undergo copyediting, typesetting, and review of the resulting proof before it is published in its final citable form. Please note that during the production process errors may be discovered which could affect the content, and all legal disclaimers that apply to the journal pertain.

Conflict of interest: Dr. Jill Smith has intellectual property rights and is a co-inventor on a US patent for the use of naltrexone in inflammatory bowel disease. This disclosure was provided to all study participants. She has no financial relationships relevant to this article to disclose. The statistical analysis of the data sets relating to efficacy and safety were independently determined by a biostatistician who has no conflict of interest. 


\section{Keywords}

IBD; LDN; Opioid receptors

\section{INTRODUCTION}

There is an unmet need for new drug therapies to treat children with Crohn's disease.

Although anti-tumor necrosis factor (TNF) agents, such as infliximab, have markedly helped children with moderate to severe Crohn's disease acutely ${ }^{1}$, still approximately $40 \%$ do not respond to biologics. Furthermore, many patients cannot continue anti-TNF agents due to untoward side effects or resistance ${ }^{2,3}$, and suppression of the immune system with the biologic agents may increase the risk of opportunistic infections ${ }^{4}$. The use of anti-TNFa compounds in conjunction with thiopurines may also increase the risk of a rare but fatal condition called hepatosplenic lymphoma which is reported primarily in adolescents and young adults 5,6 . Hence, safety is an important factor when using medications tested in adults for pediatric patients.

Unlike adults, children with Crohn's disease may experience a unique set of complications such as growth failure ${ }^{7}$, school absence, malnutrition, and depression ${ }^{8}$. Young children who have had IBD a short period of time may not have established adaptive responses such as tissue remodeling or fibrosis as adults. Additionally, the immune system in children may be different from adults in that a child's response and development of mucosal immunity to commensal bacterial and food antigens may be less mature. ${ }^{9}$ For these reasons, the response rates observed, dosing regimens and medications used in adults with Crohn's may differ for pediatrics.

Endogenous opioids exert their effect by the interaction with one of the three classical opioids receptors $\mu, \kappa$, and $\delta$ which are G-protein-coupled receptors (GPCRs) ${ }^{10}$. Opioids and their receptors have been shown to be involved in inflammation and immune cells express opioid receptors that bind both agonists and antagonists ${ }^{11}$. Naltrexone is a nonselective opioid receptor antagonist that interacts with all three opioid receptors subtypes ${ }^{12}$. Likewise cytokines and chemokines are small proteins that also interact with distinct GPCRs to act as integrators of inflammation ${ }^{13,14}$. Evidence is increasing that opioids regulate immune responses in part through their effects on cytokines and chemokines and cross-talk with the chemokine receptors ${ }^{15,} 16$.

We previously showed that naltrexone decreased inflammation of the intestine in a chemically induced animal model of inflammatory bowel disease ${ }^{17}$. In an open-labeled clinical trial, oral naltrexone therapy significantly improved Crohn's Disease Activity Index (CDAI) scores in $89 \%$ of adults ${ }^{18}$. In a larger double blind placebo controlled trial, naltrexone significantly lowered the CDAI scores in $88 \%$ of subjects $(\mathrm{p}=0.009)$ and promoted mucosal healing by colonoscopies in $78 \%$ with the Crohn's Disease Index of Severity score (CDEIS) compared to placebo-treated controls $(\mathrm{p}=0.008){ }^{19}$. These prior investigations with the opioid antagonist support the anti-inflammatory actions of this compound. The purpose of this current pilot study was to examine whether naltrexone can be administered safely to children with active Crohn's disease.

\section{METHODS AND PATIENTS}

\section{Study Design}

This investigation was a prospective pilot clinical trial undertaken to evaluate the safety and tolerability of oral low dose naltrexone in children with Crohn's disease. The protocol was 
approved by the Institutional Review Board of the Pennsylvania State University, and this study was registered with http://ClinicalTrials.gov website (NCT00715117). Children participants and parents were required to read and signed the informed consent. Oral naltrexone $(0.1 \mathrm{mg} / \mathrm{kg}$, not to exceed $4.5 \mathrm{mg})$ was administered in pediatric subjects ages 617 with moderate to severe Crohn's disease. The primary outcome was safety and tolerability compared to placebo. A secondary outcome was clinical response based upon a 10-point decline in Pediatric Crohn's Disease Activity Index (PCDAI) scores compared to baseline/pretreatment values. Using a block randomization schedule designed by the biostatistician with a block size of four stratified based upon location of disease, and Creactive protein (CRP) greater than $2.5 \mathrm{mg} / \mathrm{dl}$ or less than $2.5 \mathrm{mg} / \mathrm{dl}$ (normal $<1.0 \mathrm{mg} / \mathrm{dl}$ ) subjects were randomized by the investigational pharmacy department at baseline to receive either placebo or naltrexone in a blinded fashion for a period of 8 weeks (Fig. 1). The IRB and FDA did not allow a longer controlled period because they deemed it a potential risk to keep children with moderate to severe Crohn's disease on a placebo for a longer period of time and thought 8 weeks was sufficient to evaluate short term safety and toxicity. After 8 weeks blinded period, subjects taking placebo were then treated with naltrexone for 8 weeks and those initially randomized to naltrexone continued on the same therapy (a pseudo-cross over design), so all patients were treated with the experimental medication for either 8 or 16 weeks total. The treatment randomization sequence was concealed to all care providers, and patients until completion of the entire study. The investigational pharmacist kept records of the blinding.

\section{Patient Population}

Eligible participants were both male and female between the ages of 6-17, required to have confirmed Crohn's disease by endoscopic or radiographic methods for a minimum of 6 months, and have moderate to severe clinical disease activity with a PCDAI of $>30^{20}$. Inclusion criteria required stable doses of the following medications: 4-weeks for aminosalicylates and steroids, and 12-weeks for immunomodulators (i.e., thiopurines). Subjects were allowed to remain on their maintenance Crohn's medications at the same doses throughout the study. Restrictions on concurrent medications included the following: steroids greater than $10 \mathrm{mg}$ daily, anti-TNFa agents, and diphenoxylate hydrochloride and atropine sulfate (Lomotil@) were not permitted and patients had to be off biologics for a minimum of 8 weeks prior to screening. None of the patients were terminated from biologics in order to meet the inclusion criteria. Exclusion criteria included patients with ostomies, ileal-anal anastomosis, pregnancy, or abnormal liver enzymes.

\section{Study Intervention}

Naltrexone is a drug approved by the FDA at doses of $50 \mathrm{mg} /$ daily for alcohol withdrawal symptoms ${ }^{21}$. The drug used for this study was compounded at a much lower dose by Custom Prescriptions (Lancaster, PA) and prescribed under an IND number issued to the Principal Investigator from the Food and Drug Administration. For children age 10 or greater and weighing at least $45 \mathrm{~kg}, 4.5 \mathrm{mg}$ of naltrexone or placebo was packaged in \#4 capsules with the filler avacil PH-105. For children under age 10 or less than $45 \mathrm{~kg}$, naltrexone was dispensed in liquid form according to weight (at $0.1 \mathrm{mg} / \mathrm{kg}$ ). Placebo capsules were compounded with filler and identical in size and appearance to the active compound. The banana flavored syrup placebo control prepared for the liquid formulation was indistinguishable in appearance and taste from the active compound in solution.

\section{Study Outcome Measures}

The primary outcome of this pilot trial was to determine the safety and toxicity of administering naltrexone in children by measuring laboratory parameters and recording any potential side effects. The secondary outcome was the effects of naltrexone therapy on the 
disease activity with a clinical response defined as a 10-point decline in the PCDAI score from pretreatment and remission was defined as a score $<10^{20,22}$. The score was tabulated from a patient diary which included a record of frequency of diarrhea, abdominal pain, general well-being, temperature, physical exam, weight, and laboratory tests (erythrocyte sedimentation rate $[\mathrm{ESR}]$ and hematocrit). The information gathered on the diary corresponded to 7 days prior to each clinic visit. Comparisons were also made between the naltrexone-treated and placebo-treated groups at baseline and week- 8 and between pretreatment PCDAI scores of naltrexone.

Another parameter of Crohn's disease activity utilized in this study was the modified Harvey-Bradshaw index that does not include laboratory indices and utilizes a 24-hr analysis rather than a 7-day history ${ }^{23}$. A standardized pediatric quality of life survey specifically directed toward children with IBD, the IMPACT-III survey ${ }^{24}$, was completed by subjects at the initiation visit and monthly thereafter.

\section{Statistical Analysis}

The information used to calculate the number of subjects for each arm of the study was from the information we have from our trials in adults ${ }^{18,19}$. In the adult pilot trial, 15 of 17 subjects (88\%) responded favorably to natrexone. In the proposed study, it was assumed that $80 \%$ would respond to naltrexone and that no more than $25 \%$ of the placebo / untreated group would respond. A response to therapy was defined as a decline of 10 points in the PCDAI score so that the proportional hazard regression analysis was appropriate for the statistical comparison between the two arms. Allowing for $10 \%$ withdrawal rate, a sample size of twenty four subjects yielded an $80 \%$ statistical power with a two-sided, 0.5 significance level for detecting hazard for the naltrexone group. With this information 12 subjects were needed for the treatment arm of the study. The power calculations were performed using STPLAN version 4.1. The current investigation was designed as a pseudocross over study to increase the number of participants treated with naltrexone for an eight week time period and also to have a placebo control arm for the safety analysis. Descriptive statistics (mean, median, standard deviation, minimum and maximum) were calculated at baseline, pretreatment with naltrexone, after 8 and 16 weeks of naltrexone therapy, and after 8 weeks of placebo for each of the PCDAI outcome measurements. Any patient who exhibited a flare in clinical activity (an increase in the PCDAI score of 12.5) was rescued with steroids, the study drug or placebo was discontinued, and the data was included in the analysis as intent-to treat analysis. Differences between the mean of both pretreatment PCDAI scores and mean scores at the end of an 8-week course of naltrexone therapy were compared by paired student-t test with clinical significance accepted at the 0.05 level. The side effects in the naltrexone versus the placebo-treated subjects were analyzed by the Fisher's exact test. All analyses were carried out using SAS software version 9.1 (SAS Inc, Cary, NC).

\section{RESULTS}

\section{Demographics and Patient Characteristics}

Fourteen subjects were consented and enrolled into the study; however, two subjects were considered screening failures and were not randomized or treated based upon PCDAI scores less than 30 (i.e., 12 subjects were randomized and treated). The patient demographics are shown in Table 1 with more females than males being treated and ranging in age from 8-17. Two of the participants had previously failed or were allergic to anti-TNFa biologics. Twothirds of the subjects were taking aminosalicylates and three-fourths were on thiopurines. None of the participants were taking methotrexate. These baseline medications were continued at the same dose throughout the study. Four patients in each group had ileocolitis, 
and six had non-stricturing / non-penetrating disease ( 2 in placebo and 4 in naltrexone treated groups)

\section{Side Effects}

The frequency of side effects reported during the study is shown in Table 2. Few side effects were reported and there was no difference in the incidence of these complaints between patients receiving naltrexone compared to placebo. Some nonspecific symptoms were recorded both in those taking placebo and naltrexone, some of which may have been related to the underlying inflammatory bowel disease (i.e., nausea and decreased appetite). More participants on naltrexone reported unusual dreams; however, the rate was not significant compared to placebo.

\section{Safety and Toxicity}

No significant adverse laboratory abnormalities were detected in subjects treated with naltrexone compared to placebo (Table 3). In particular, there were no increases in the serum transaminases, electrolyte, renal or glucose abnormalities noted. Prealbumin levels improved 2.5-fold more in naltrexone treated patients over placebo control, suggesting improved nutritional status. ESR values decreased 2.4 more in naltrexone treated patients compared to placebo treated patients during the first eight weeks of the study. Additionally, other parameters of inflammation (white blood count and C-reactive protein) also improved, but either due to the small cohort or the inclusion of data from the subject who flared by intent-to-treat analysis, these differences were not significant.

\section{Clinical Activity Scores}

Baseline PCDAI scores were elevated in all participants consistent with moderate to severe clinical activity of Crohn's disease according to the Hyam's criteria ${ }^{20}$. Significant improvement was observed $(\mathrm{p}=0.005)$ when comparing pretreatment PCDAI scores $(34.2 \pm$ 3.3) to scores after eight weeks on naltrexone therapy $(21.7 \pm 3.9)$ (Fig. 2A). However, since the individual group sizes were small and also due to a small 'placebo effect,' the differences between placebo-treated and naltrexone-treated subjects did not reach statistical significance. Only naltrexone treated subjects and not placebo treated subjects had PCDAI scores less than 30 after the first 8 weeks. The Harvey Bradshaw Index activity was significantly improved in naltrexone-treated subjects compared to placebo at week 4 $(\mathrm{p}=0.03)$, but this difference was not significant at week 8 .

Individual participant clinical responses by the PDCAI scores are shown in Figure 2B comparing baseline values to those at the end of the study $(\mathrm{p}=0.001)$. One subject experienced a flare in Crohn's symptoms during the study. Twenty-five percent of those treated with naltrexone were considered in remission (score < 10) and 67\% had improved with mild disease activity (decrease PCDAI score by at least 10 points) at the end of the study.

\section{Quality of Life Survey}

An updated version of the survey called the IMPACT III ${ }^{24}$ was used in this study and examined five major categories influencing the quality of life in children with Crohn's disease including bowel symptoms, systemic symptoms, emotional well-being, social wellbeing, and body image perception. Results of the IMPACT III quality of Life Survey are displayed in Figure 3. Two categories significantly improved during the course of this study from baseline $(\mathrm{p}=0.035)$ with administration of naltrexone including the systemic symptoms and social well-being. 


\section{DISCUSSION}

In the current study, an opioid receptor antagonist was tested in children with moderate to severe active Crohn's disease for safety and toxicity. In order to determine whether the low dosage of naltrexone utilized $(0.1 \mathrm{mg} / \mathrm{kg}$, up to $4.5 \mathrm{mg})$ had any untoward effects or toxicity in children, half of the children received a placebo for the first eight weeks of the study. Naltrexone has been reported to induce hepatotoxicity at high doses ${ }^{25}$ prompting the FDA to issue a black box warning for the use of this medication. Subsequent studies have not substantiated liver toxicity especially when administered at lower doses ${ }^{26}$ and in the current study no evidence of hepatotoxicity as measured by serum transaminases was identified. Moreover, no abnormalities occurred in regards to bone marrow toxicity, electrolyte disturbances, or renal dysfunction. Naltrexone is known to be unpalatable and therefore the liquid formulation used for children in the study was flavored. Only one child complained that he disliked the banana flavoring, and this patient was receiving the placebo. Therefore, we conclude that at the doses used in the current study naltrexone were well tolerated and appear to be safe for short-term use in pediatrics. The side effects related to naltrexone with longer administration or chronic use are unknown in children with Crohn's disease.

Although the primary outcome of this study was not efficacy in this small cohort, information was collected on the potential use of naltrexone to improve clinical Crohn's disease activity. Based upon the validated PCDAI scoring system ${ }^{20}$, subjects treated with naltrexone for 8 weeks had significant decreases in the activity scores from baseline suggesting improvement in the Crohn's disease. At the completion of the study, twenty-five percent achieved a clinical remission and sixty-seven percent had a significant response to therapy which is higher than what would be expected for a spontaneous response. In our prior adult clinical trials ${ }^{19}$, we found that naltrexone improved clinical activity scores in over $85 \%$ of adults. The current pilot trial suggests that children may also respond to naltrexone, although a larger study is needed to make valid comparisons to placebo controls. The incidence of response with placebo has been reported to be as high as $35 \%$ in adult subjects with Crohn's disease in part due to the subjective component of the CDAI scoring system; the response of those on placebo in the current study was low at $12 \%$ compared to baseline PCDAI values.

In chronic disease states, it is important to evaluate whether therapy also improves the overall well-being and quality of life of patients. It is increasingly clear that biological data and disease severity scores alone are insufficient to assess a patient's overall health status and that additional information relating to quality of life and psychosocial factors should also be obtained 27,28 . A quality of life survey has been developed in adults with inflammatory bowel disease: the IBDQ quality of life survey ${ }^{29}$. Unfortunately, this survey is not a good reflection of the true quality of life as it relates to a child with IBD. A specific quality of life survey, the IMPACT questionnaire ${ }^{24,30}$, has been developed and validated for children with inflammatory bowel disease. The results of the IMPACT III survey conducted in this investigation propose that naltrexone therapy did not adversely alter quality of life in children and may improve some areas of overall wellbeing and psychosocial issues.

There were some strengths as well as drawbacks to this phase 1 pilot trial. Weaknesses included the fact that the study involved only a single site and small sample size. The advantage of a pseudo-cross over study design is that the sample size of those receiving active drug is increased and this design also aids in patient recruitment. However, a disadvantage to this design is that all subjects knew that at some point in the 16-week period that they would receive active drug perhaps increasing the subjective response data. A strength of this study is that rather than using baseline PCDAI scores to compare to the 8- 
week treatment period, the PCDAI scores immediately before naltrexone therapy (pretreatment scores) were used and these independent values were obtained at different times (i.e., at baseline for those initially treated naltrexone and week- 8 for placebo treated subjects). Although some studies average the scores of patients in the lead-in time when treated with a placebo rather than using the pretreatment score, using the value immediately prior to therapy (as done in this study) is a more stringent approach. Endoscopic healing is becoming the gold standard for determination of efficacy in IBD trials; neither colonoscopies nor calprotectin stool assays were performed in the current study to evaluate mucosal healing. Although the PCDAI scores have traditionally been utilized to determine response, this scoring system includes subjective data from a diary which may influence the score. In spite of some of these short comings, the results of this investigation are nevertheless provocative and demand another larger controlled clinical trial.

Treating Crohn's disease with an opioid antagonist is certainly innovative. For years doctors have known that narcotic analgesics affect the gastrointestinal motility and drugs such as paregoric and codeine have been used to slow bowel transit and control acute diarrhea. In the TREAT registry analysis Lichtenstein and colleagues ${ }^{31}$ determined that narcotic use was associated with a 1.5 -fold increased risk of mortality and a 3 -fold risk of serious infection compared to Crohn's disease patients not receiving narcotic analgesics suggesting that agonist opiate drugs worsen the inflammatory disease process. Indeed Cross and colleagues ${ }^{32}$ have reported that Crohn's disease activity is worse in patients taking narcotics suggesting that narcotic use aggravates IBD. These studies substantiate the idea that a drug that blocks opioids receptors, i.e., narcotic antagonist (naltrexone), could reverse the inflammation and lessen disease activity.

The mechanism by which a low-dose of naltrexone interacts with the opioids receptors compared to the higher dose is unknown. One theory proposed by Crain and Shen ${ }^{33}$ is that opioid receptors have dual affinities (low and high) and the effect of agonists depends upon the dominant receptor population. The excitatory opioids response is selectively blocked by low doses of opioid antagonists such as naltrexone, but the inhibitory response is not ${ }^{33}$. Since opioids play a role on intestinal motility, secretion, and visceral pain ${ }^{34}$, opioid antagonists have also been studied using the lower dose in patients with irritable bowel syndrome (IBS) ${ }^{35,36}$. In IBS, it was proposed that the lower dose of naltrexone would selectively antagonize the excitatory opioids receptor function in the sensory neurons. Although similar mechanisms may also be involved in Crohn's patients, the interaction of opioid antagonists with nerves should have no effect on mucosal inflammation. In inflammatory bowel disease the effects of opioid antagonists most likely have multiple mechanisms of action including the interaction with nerve tissues and also with immune mediated cells.

Some advantages of naltrexone therapy include its oral route of administration and the oncea-day dosing may improve patient compliance, especially in teenagers. Naltrexone is inexpensive making this therapy cost efficient if found to be efficacious for maintenance in Crohn's disease. The results of this pilot study suggest that opioid receptor antagonism at a low dose appears to be safe, well tolerated and possibly effective in improving clinical activity and quality of life in children with Crohn's disease. Larger controlled trials and long-term studies are warranted to confirm its efficacy and long term safety.

\section{Acknowledgments}

We thank Dr. Otley and colleagues for granting permission to use the IMPACT-III the quality of life survey. We thank the nursing staff from the General Clinical Research Center at the Pennsylvania State University College of Medicine for their assistance and care of the participants in this clinical trial. 
Funded by: Supported by a gift from the GivenShare Inc., and NIH grants M01RR010732 and C06RR016499.

\section{REFERENCES}

1. Hyams J, Crandall W, Kugathasan S, et al. Induction and maintenance infliximab therapy for the treatment of moderate-to-severe Crohn's disease in children. Gastroenterology. 2007; 132:863-873. [PubMed: 17324398]

2. Bell S, Kamm MA. Antibodies to tumour necrosis factor alpha as treatment for Crohn's disease. Lancet. 2000; 355:858-860. [PubMed: 10752696]

3. Sandborn WJ, Hanauer SB. Antitumor necrosis factor therapy for inflammatory bowel disease: a review of agents, pharmacology, clinical results, and safety. Inflamm Bowel Dis. 1999; 5:119-133. [PubMed: 10338381]

4. Toruner M, Loftus EV Jr, Harmsen WS, et al. Risk factors for opportunistic infections in patients with inflammatory bowel disease. Gastroenterology. 2008; 134:929-936. [PubMed: 18294633]

5. Mackey AC, Green L, Liang LC, et al. Hepatosplenic T cell lymphoma associated with infliximab use in young patients treated for inflammatory bowel disease. J Pediatr Gastroenterol Nutr. 2007; 44:265-267. [PubMed: 17255842]

6. Shale M, Kanfer E, Panaccione R, et al. Hepatosplenic T cell lymphoma in inflammatory bowel disease. Gut. 2008; 57:1639-1641. [PubMed: 18667489]

7. Motil KJ, Grand RJ, Davis-Kraft L, et al. Growth failure in children with inflammatory bowel disease: a prospective study. Gastroenterology. 1993; 105:681-691. [PubMed: 8359640]

8. Van Limbergen J, Russell RK, Drummond HE, et al. Definition of phenotypic characteristics of childhood-onset inflammatory bowel disease. Gastroenterology. 2008; 135:1114-1122. [PubMed: 18725221]

9. Underwood MA, Bevins CL. Defensin-barbed innate immunity: clinical associations in the pediatric population. Pediatrics. 2010; 125:1237-1247. [PubMed: 20478936]

10. Waldhoer M, Bartlett SE, Whistler JL. Opioid receptors. Annu Rev Biochem. 2004; 73:953-990. [PubMed: 15189164]

11. McCarthy L, Wetzel M, Sliker JK, et al. Opioids, opioid receptors, and the immune response. Drug Alcohol Depend. 2001; 62:111-123. [PubMed: 11245967]

12. Raynor K, Kong H, Chen Y, et al. Pharmacological characterization of the cloned kappa-, delta-, and mu-opioid receptors. Mol Pharmacol. 1994; 45:330-334. [PubMed: 8114680]

13. Parenty G, Appelbe S, Milligan G. CXCR2 chemokine receptor antagonism enhances DOP opioid receptor function via allosteric regulation of the CXCR2-DOP receptor heterodimer. Biochem J. 2008; 412:245-256. [PubMed: 18307412]

14. White FA, Bhangoo SK, Miller RJ. Chemokines: integrators of pain and inflammation. Nat Rev Drug Discov. 2005; 4:834-844. [PubMed: 16224455]

15. Finley MJ, Happel CM, Kaminsky DE, et al. Opioid and nociceptin receptors regulate cytokine and cytokine receptor expression. Cell Immunol. 2008; 252:146-154. [PubMed: 18279847]

16. Rogers TJ, Peterson PK. Opioid G protein-coupled receptors: signals at the crossroads of inflammation. Trends Immunol. 2003; 24:116-121. [PubMed: 12615205]

17. Matters GL, Harms JF, McGovern C, et al. The opioid antagonist naltrexone improves murine inflammatory bowel disease. J Immunotoxicol. 2008; 5:179-187. [PubMed: 18569389]

18. Smith JP, Stock H, Bingaman S, et al. Low-dose naltrexone therapy improves active Crohn's disease. Am J Gastroenterol. 2007; 102:820-828. [PubMed: 17222320]

19. Smith JP, Bingaman SI, Ruggiero F, et al. Therapy with the opioid antagonist naltrexone promotes mucosal healing in active Crohn's disease: a randomized placebo-controlled trial. Dig Dis Sci. 2011; 56:2088-2097. [PubMed: 21380937]

20. Hyams JS, Ferry GD, Mandel FS, et al. Development and validation of a pediatric Crohn's disease activity index. J Pediatr Gastroenterol Nutr. 1991; 12:439-447. [PubMed: 1678008]

21. Petrakis I, Ralevski E, Nich C, et al. Naltrexone and disulfiram in patients with alcohol dependence and current depression. J Clin Psychopharmacol. 2007; 27:160-165. [PubMed: 17414239]

22. Lloyd-Still JD, Green OC. A clinical scoring system for chronic inflammatory bowel disease in children. Dig Dis Sci. 1979; 24:620-624. [PubMed: 467213] 
23. Harvey RF, Bradshaw JM. A simple index of Crohn's-disease activity. Lancet. 1980; 1:514. [PubMed: 6102236]

24. Otley A, Smith C, Nicholas D, et al. The IMPACT questionnaire: a valid measure of health-related quality of life in pediatric inflammatory bowel disease. J Pediatr Gastroenterol Nutr. 2002; 35:557-563. [PubMed: 12394384]

25. Mitchell JE. Naltrexone and hepatotoxicity. Lancet. 1986; 1:1215. [PubMed: 2871452]

26. Yen MH, Ko HC, Tang FI, et al. Study of hepatotoxicity of naltrexone in the treatment of alcoholism. Alcohol. 2006; 38:117-120. [PubMed: 16839858]

27. Eiser C, Morse R. Quality-of-life measures in chronic diseases of childhood. Health Technol Assess. 2001; 5:1-157. [PubMed: 11262421]

28. Griffiths AM, Otley AR, Hyams J, et al. A review of activity indices and end points for clinical trials in children with Crohn's disease. Inflamm Bowel Dis. 2005; 11:185-196. [PubMed: 15677913]

29. Irvine EJ, Feagan B, Rochon J, et al. Quality of life: a valid and reliable measure of therapeutic efficacy in the treatment of inflammatory bowel disease. Canadian Crohn's Relapse Prevention Trial Study Group. Gastroenterology. 1994; 106:287-296. [PubMed: 8299896]

30. Griffiths AM, Nicholas D, Smith C, et al. Development of a quality-of-life index for pediatric inflammatory bowel disease: dealing with differences related to age and IBD type. J Pediatr Gastroenterol Nutr. 1999; 28:S46-S52. [PubMed: 10204526]

31. Lichtenstein GR, Feagan BG, Cohen RD, et al. Serious infections and mortality in association with therapies for Crohn's disease: TREAT registry. Clin Gastroenterol Hepatol. 2006; 4:621-630. [PubMed: 16678077]

32. Cross RK, Wilson KT, Binion DG. Narcotic use in patients with Crohn's disease. Am J Gastroenterol. 2005; 100:2225-2229. [PubMed: 16181373]

33. Crain SM, Shen K. Enhanced analgesic potency and reduced tolerance of morphine in 129/SvEv mice: evidence for a deficiency in GM1 ganglioside-regulated excitatory opioid receptor functions. Brain Res. 2000; 856:227-235. [PubMed: 10677630]

34. Fioramonti J, Bueno L. Centrally acting agents and visceral sensitivity. Gut. 2002; 51(Suppl 1):i91-i95. [PubMed: 12077076]

35. Hawkes ND, Rhodes J, Evans BK, et al. Naloxone treatment for irritable bowel syndrome-- a randomized controlled trial with an oral formulation. Aliment Pharmacol Ther. 2002; 16:16491654. [PubMed: 12197844]

36. Kariv R, Tiomny E, Grenshpon R, et al. Low-dose naltreoxone for the treatment of irritable bowel syndrome: a pilot study. Dig Dis Sci. 2006; 51:2128-2133. [PubMed: 17080248] 


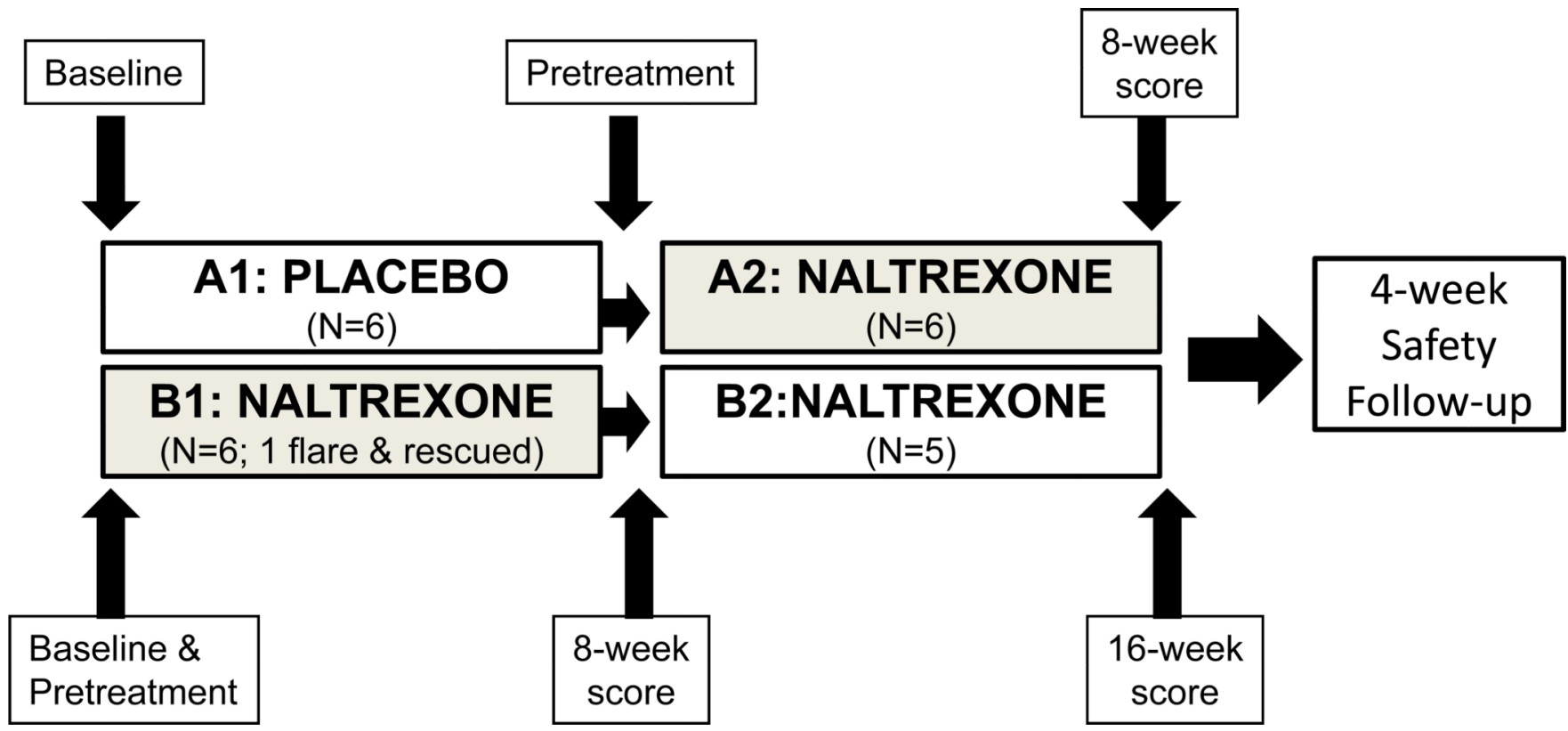

FIGURE 1.

Study Design. At baseline, subjects were randomized to either naltrexone or placebo therapy for 8 weeks. After 8-weeks the placebo treated subjects crossed over to treatment with naltrexone and the subjects initially randomized to active drug continued on naltrexone. For analysis, PCDAI scores obtained at the pretreatment points in each group were compared to the combined PCDAI scores after 8 weeks of naltrexone therapy (gray shaded boxes). Comparisons in PCDAI scores between Baseline and 16 weeks of naltrexone therapy were also evaluated. 
A.

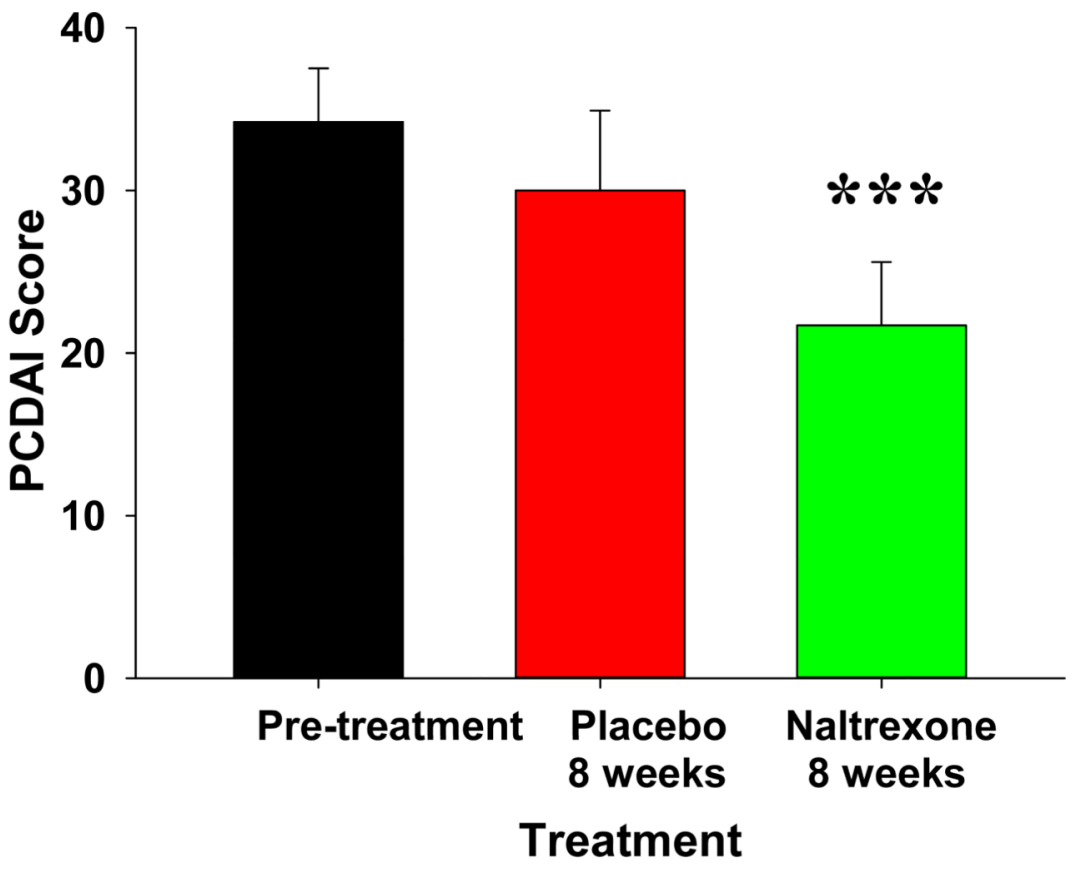

B.

\section{Changes in PCDAI Scores}

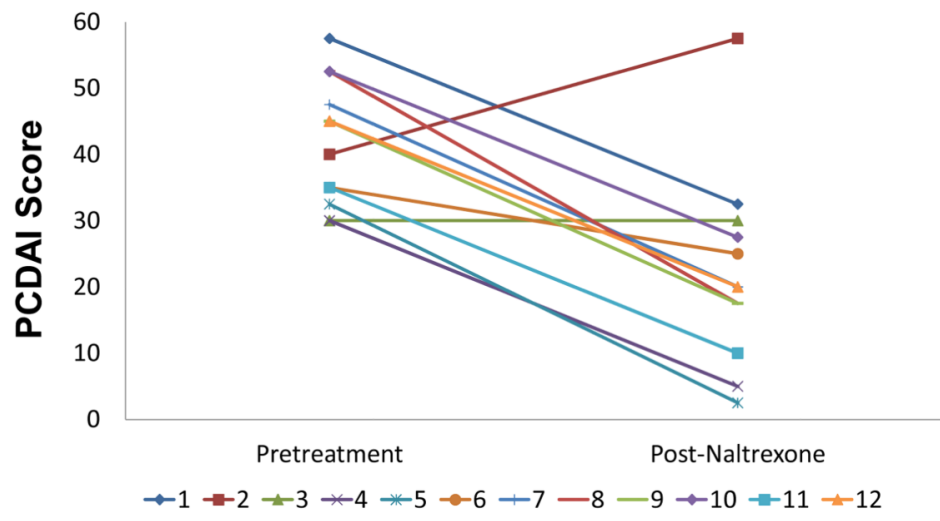

FIGURE 2.

A. Pediatric Crohn's Disease Activity Index Scores (PCDAI). Mean pretreatment PCDAI scores show the patients had moderate to severe disease activity. Participants showed a significant decrease in mean PCDAI scores after 8 weeks of naltrexone but not after placebo. $* * * \mathrm{p}=0.005$ compared to pretreatment values. B. PCDAI scores are shown in individual subjects at Baseline and after exposure to naltrexone for either 8 or 16 weeks. Significant improvement was observed $* * * \mathrm{p}=0.001$. 


\section{IMPACT III Quality of Life}

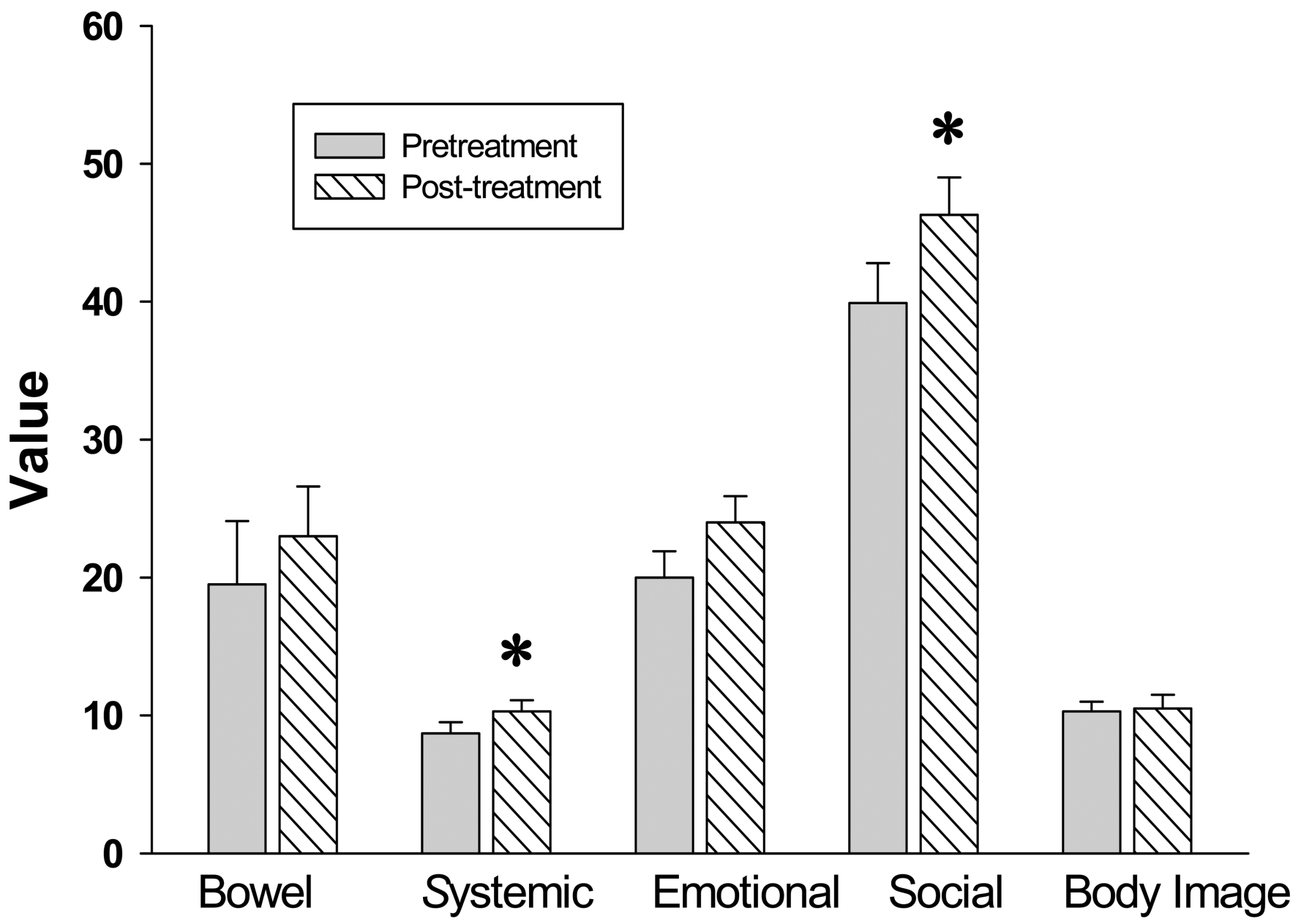

FIGURE 3.

System results from the IMPACT III quality of life survey. Results from the five categories of the IMPACT III survey are shown comparing baseline values to values after therapy with naltrexone. Systemic Crohn's disease symptoms and social well-being both significantly improved with naltrexone therapy. Columns represent mean scores \pm S.E.M.; $* \mathrm{p}=0.035$. 
TABLE 1

Patient Demographics and Concurrent Therapies

\begin{tabular}{|c|c|c|}
\hline CHARACTERISTICS & PLACEBO: Group A & NALTREXONE: Group B \\
\hline $\begin{array}{l}\text { Age (years); mean } \pm \text { S.E.M. } \\
\text { (Range, years) }\end{array}$ & $\begin{array}{c}12.2 \pm 1.4 \\
(8-17)\end{array}$ & $\begin{array}{c}13.0 \pm 1.3 \\
(9-16)\end{array}$ \\
\hline Gender, $\mathrm{N}$ & $\begin{array}{c}\text { Males } 4 \\
\text { Females } 2\end{array}$ & $\begin{array}{c}\text { Males } 1 \\
\text { Females } 5\end{array}$ \\
\hline Prior anti-TNFa therapy & 2 & 0 \\
\hline Prior gastrointestinal surgery & 1 (perianal) & 0 \\
\hline \multicolumn{3}{|l|}{ Phenotype: } \\
\hline B1 Non-stricturing /non-penetrating & B1 2 & B1 4 \\
\hline B2 Stricturing & B2 2 & B2 1 \\
\hline B3 Penetrating & B3 2 & B3 1 \\
\hline \multicolumn{3}{|c|}{ Concomitant meds for Crohn's ( $\mathrm{N}=$ number of patients) } \\
\hline Aminosalicylates & 3 & 6 \\
\hline Immunomodulators (thiopurines) & 5 & 4 \\
\hline Corticosteroids & 1 & 2 \\
\hline Antibiotics & 1 & 1 \\
\hline \multicolumn{3}{|l|}{ Location of disease: } \\
\hline L1 Terminal Ileum & L1 0 & L1 0 \\
\hline L2 Colon & $\mathrm{L} 22$ & L2 1 \\
\hline L3 Ileocolon & L3 4 & L3 4 \\
\hline L4 Upper GI & L4 0 & L4 1 \\
\hline \multicolumn{3}{|l|}{ C-R P (normal <1.0) } \\
\hline & $3.4 \pm 2.3$ & $3.7 \pm 1.8$ \\
\hline
\end{tabular}

S.E.M. $=$ standard error of mean, $\mathrm{N}=$ number, $\mathrm{kg}=$ kilograms, $\mathrm{TNF}=$ tumor necrosis factor 
TABLE 2

Number of Patients Reporting Side Effects

\begin{tabular}{l|c|c|c|}
\hline Side Effect /Symptom & Placebo & Naltrexone & p valve \\
\hline Sleep disturbance & 2 & 2 & 1.0 \\
Unusual dreams & 0 & 2 & 0.45 \\
Twitching & 1 & 1 & 1.0 \\
Headaches & 1 & 0 & 1.0 \\
Decreased appetite & 1 & 0 & 1.0 \\
Nausea & 0 & 1 & 1.0 \\
Hair loss & 1 & 0 & 1.0 \\
Fatigue & 1 & 0 & 1.0 \\
Flushed ears & 0 & 1 & 1.0 \\
Papules, rash & 1 & 0 & 1.0 \\
Double vision & 0 & 1 & 1.0 \\
\hline
\end{tabular}

Statistics were done by the Fisher's exact test. 


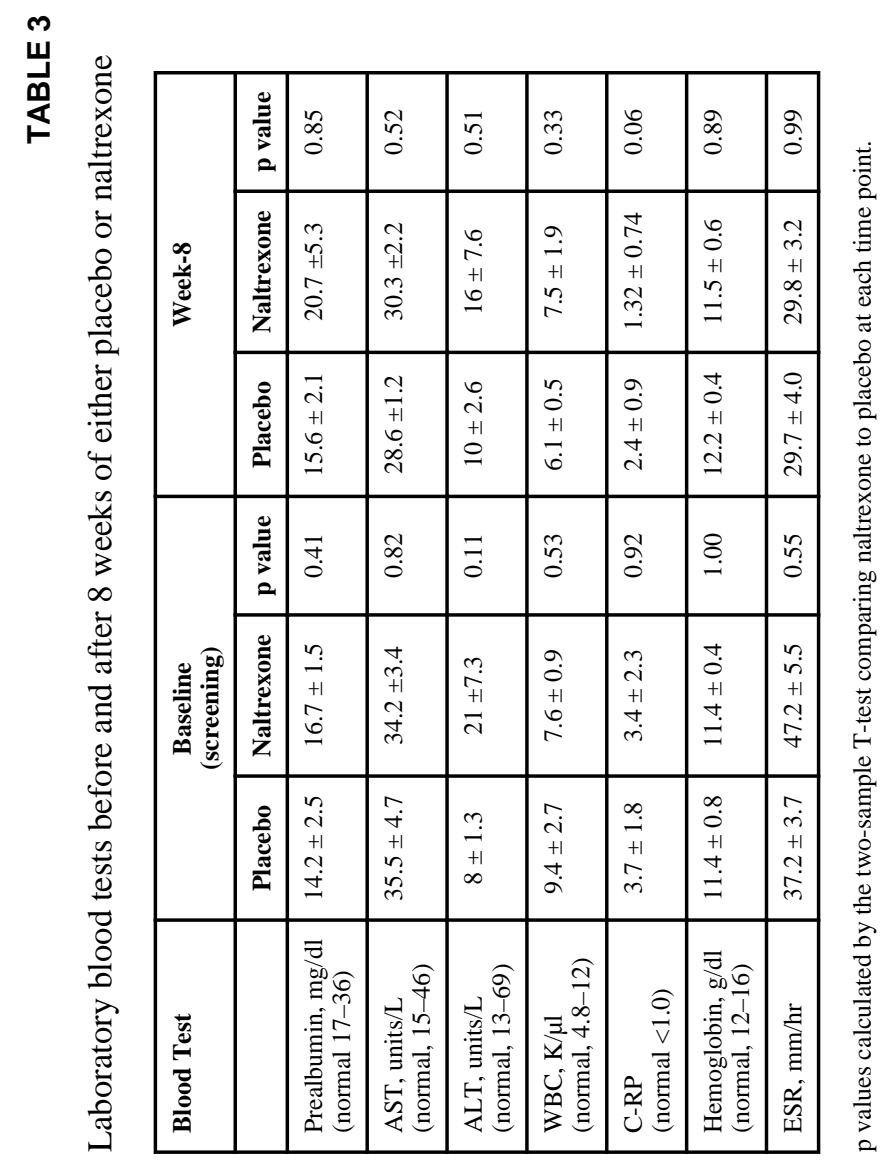

J Clin Gastroenterol. Author manuscript; available in PMC 2014 April 01. 